ACCEPTED MANUSCRIPT

\title{
The influence of electrospinning parameters on polydioxanone scaffold properties
}

To cite this article before publication: Bilal Ahmad et al 2017 Biomed. Phys. Eng. Express in press https://doi.org/10.1088/2057-1976/aa979f

\section{Manuscript version: Accepted Manuscript}

Accepted Manuscript is "the version of the article accepted for publication including all changes made as a result of the peer review process, and which may also include the addition to the article by IOP Publishing of a header, an article ID, a cover sheet and/or an 'Accepted

Manuscript' watermark, but excluding any other editing, typesetting or other changes made by IOP Publishing and/or its licensors"

This Accepted Manuscript is @ 2017 IOP Publishing Ltd.

During the embargo period (the 12 month period from the publication of the Version of Record of this article), the Accepted Manuscript is fully protected by copyright and cannot be reused or reposted elsewhere.

As the Version of Record of this article is going to be / has been published on a subscription basis, this Accepted Manuscript is available for reuse under a CC BY-NC-ND 3.0 licence after the 12 month embargo period.

After the embargo period, everyone is permitted to use copy and redistribute this article for non-commercial purposes only, provided that they adhere to all the terms of the licence https://creativecommons.org/licences/by-nc-nd/3.0

Although reasonable endeavours have been taken to obtain all necessary permissions from third parties to include their copyrighted content within this article, their full citation and copyright line may not be present in this Accepted Manuscript version. Before using any content from this article, please refer to the Version of Record on IOPscience once published for full citation and copyright details, as permissions will likely be required. All third party content is fully copyright protected, unless specifically stated otherwise in the figure caption in the Version of Record.

View the article online for updates and enhancements. 


\section{The influence of electrospinning parameters on polydioxanone}

\section{scaffold properties}

\section{Bilal S. Ahmad ${ }^{1}$, Marilys Blanchy ${ }^{2}$, Gael Mbele ${ }^{3}$, Laetitia Pidial ${ }^{4}$ Valerie Vanneaux ${ }^{3}$, Philippe}

Menasché, ${ }^{4,5}$, Gareth R. Williams ${ }^{1 *}$ and David Kalfa ${ }^{6 *}$

${ }^{1}$ UCL School of Pharmacy, University College London, London, UK

${ }^{2}$ RESCOLL Inc., Pessac, France

${ }^{3}$ Laboratory of Cell Therapy, Assistance Publique- Hôpitaux de Paris APHP, Saint-Louis Hospital, Paris-Diderot University, Paris, France

${ }^{4}$ Department of Cardiovascular Surgery and INSERM U 970, Hôpital Européen Georges Pompidou, APHP, Paris, France

${ }^{5}$ University Paris Descartes, Sorbonne Paris Cité, Paris, France

${ }^{6}$ TEH-Tube scientific coordinator, New York, USA

\section{Corresponding authors:}

David Kalfa, MD, PhD, Morgan Stanley Children's Hospital - New-York Presbyterian - Columbia University Medical Center, Pediatric Cardiac Surgery, 3959 Broadway, New York, NY 10032, USA. Tel.: +1 212 (305)-2688; fax: +1 212 (305)-4408. E-mail: davidkalfa@gmail.com

Gareth R. Williams, DPhil, University College London, UCL School of Pharmacy, 29-39 Brunswick Square, London, WC1N 1AX, UK. Tel : +44 (0) 207753 5868. E-mail: g.williams@ucl.ac.uk 


\section{Abstract}

Conduits currently used to reconstruct the right ventricular outflow tract (RVOT) have no growth potential and require reoperations, resulting in an increased level of morbidity and mortality. This work investigates the effect of electrospinning parameters on the mechanical properties and biocompatibility of bioresorbable tubular scaffolds, as part of a program to develop a tissueengineered valved tube for RVOT replacement. Electrospinning was used to develop tubular scaffolds of polydioxanone, with the experimental parameters systematically varied. Three electrospinning parameters (volume of liquid, flow rate, and speed of mandrel rotation) were investigated, and their effects on the mechanical properties and cellular response of the scaffolds were analysed using scanning electron microscopy, X-ray diffraction, differential scanning calorimetry, gas chromatography, uniaxial tensile tests, cell viability and cytotoxicity assays. Mechanical properties were compared to those of the native RVOT reported in the literature. Increasing the mandrel rotation speed tended to increase fibre alignment slightly, and led to more profound rises in the stress at failure and Young's modulus. An increase in flow rate also increased the rigidity of the tubes. Cell viability and cytotoxicity assays showed all the tubes produced to have excellent biocompatibility. Through variation of the processing parameters, it is possible to tune mechanical properties of medical-grade polymer tubes over a wide range. By using/a mandrel rotation speed of $50 \mathrm{rpm}$ and a flow rate of 20 $\mathrm{mL} / \mathrm{h}$ or higher we can prepare materials with Young's modulus, strain at failure, and tensile stress close to the native tissue. Electrospinning therefore offers great promise in the development of scaffolds to match the properties of the native RVOT, paving the way to a future bioresorbable device to replace the RVOT in children.

Keywords: Electrospinning; Polydioxanone; Right ventricular outflow tract (RVOT); Scaffold 
defects require reconstruction of the right ventricular outflow tract (RVOT). Current clinical solutions for RVOT replacement are based on inert biomaterials lacking regeneration potential. These can lead to calcification, stenosis and, consequently, multiple reoperations with a significant risk of morbidity and mortality: up to $88 \%$ of these conduits have to be replaced within 5 years of implantation [2]. Thus, much research has been undertaken into finding suitable materials and methods that can be used to create a scaffold able to mimic the native artery and valve architecture, elicit a favourable cellular response, degrade after the host's own cells have repopulated the scaffold, and which possesses appropriate mechanical properties $[3,4]$. As part of a program targeted at developing a resorbable valved tube for replacement of the RVOT, we initially demonstrated the ability of a monovalved polydioxanone (PDO) patch to restore a functional RVOT in growing lambs [5]. Subsequently, we showed that peptide-functionalized polymers may be substituted for cell-loaded materials in such an application [6].

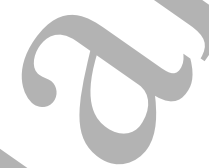

Design of the polymeric scaffold remains a challenging task. For the scaffold to be effective, it must be capable of regulating a positive cellular function without compromising tissue-specific mechanical properties [7]. Appropriate mechanical properties must be retained throughout the life cycle of the scaffold inside the body. This can only be achieved if the degradation of the arterial scaffold caters for the complex haemodynamics of the heart and temporally matches its colonization by the host cells. Therefore, the multifunctional nature of the native extra cellular matrix (ECM) must be recognized and replicated to varying degrees in the design and fabrication of such scaffolds [8]. In order to achieve this in the particular instance of the RVOT, a degradation time of 6-9 months is required.

It is known that electrospinning (ES), a technique that uses an electrical charge to draw very fine fibres from a liquid, can be used to produce scaffolds that recapitulate key structural features of the native ECM [8]. This processing strategy can be used to selectively fabricate sub-micron to micron diameter fibres from a variety of synthetic [7] and natural polymers [8]. In brief, it involves preparing a solution of a polymer in a volatile solvent, and ejecting this from a metal needle towards a grounded collector. A high $(\mathrm{kV})$ potential difference is applied between the two, resulting in evaporation of the 
solvent and the formation of fibres. In such a set-up, fibre diameter and inter-fibre pore size can be regulated by controlling the electrospinning parameters such as flow rate, applied voltage, needle-tocollector distance and composition of the electrospinning solution [9]. Varying the degree of fibre alignment and anisotropy present in an electrospun scaffold imparts non-uniform mechanical properties to the construct and may represent a source of guidance cues that can be exploited to regulate cell phenotype, cell distribution and the macroscopic properties of an engineered tissue [10].

In this work, we present an investigation into the effect of the volume of liquid dispensed, flow rate, and speed of the rotating mandrel on the mechanical properties and the cellular response of electrospun tubular scaffolds prepared using polydioxanone. The scaffolds were fully characterised, subjected to uniaxial tensile testing to determine their mechanical properties, and the cellular response explored in in vitro studies.

\section{Materials and methods}

\section{Materials}

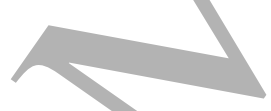

Polydioxanone (PDO; Resomer X206S) was used for scaffold production, based on the biological and mechanical characteristics and the experience of our group working with this polymer [5, 6]. PDO was acquired in the form of white granules (Evonik Industries AG, Essen, Germany) and dissolved in 1,1,1,3,3,3-hexafluoro-2-propanol (HFIP; $\geq$ 99\% purity, Sigma Aldrich, Gillingham, UK) under stirring. Different solution concentrations ranging from $5-12 \% \mathrm{w} / \mathrm{v}$ PDO were first explored before the optimum concentration $(9 \% \mathrm{w} / \mathrm{v})$ was selected on the basis that it produced the highest quality fibres.

\section{Electrospinning}

The apparatus used is illustrated in Fig. 1. A rotating mandrel (Fig. 1a) was employed to generate tubular scaffolds. 


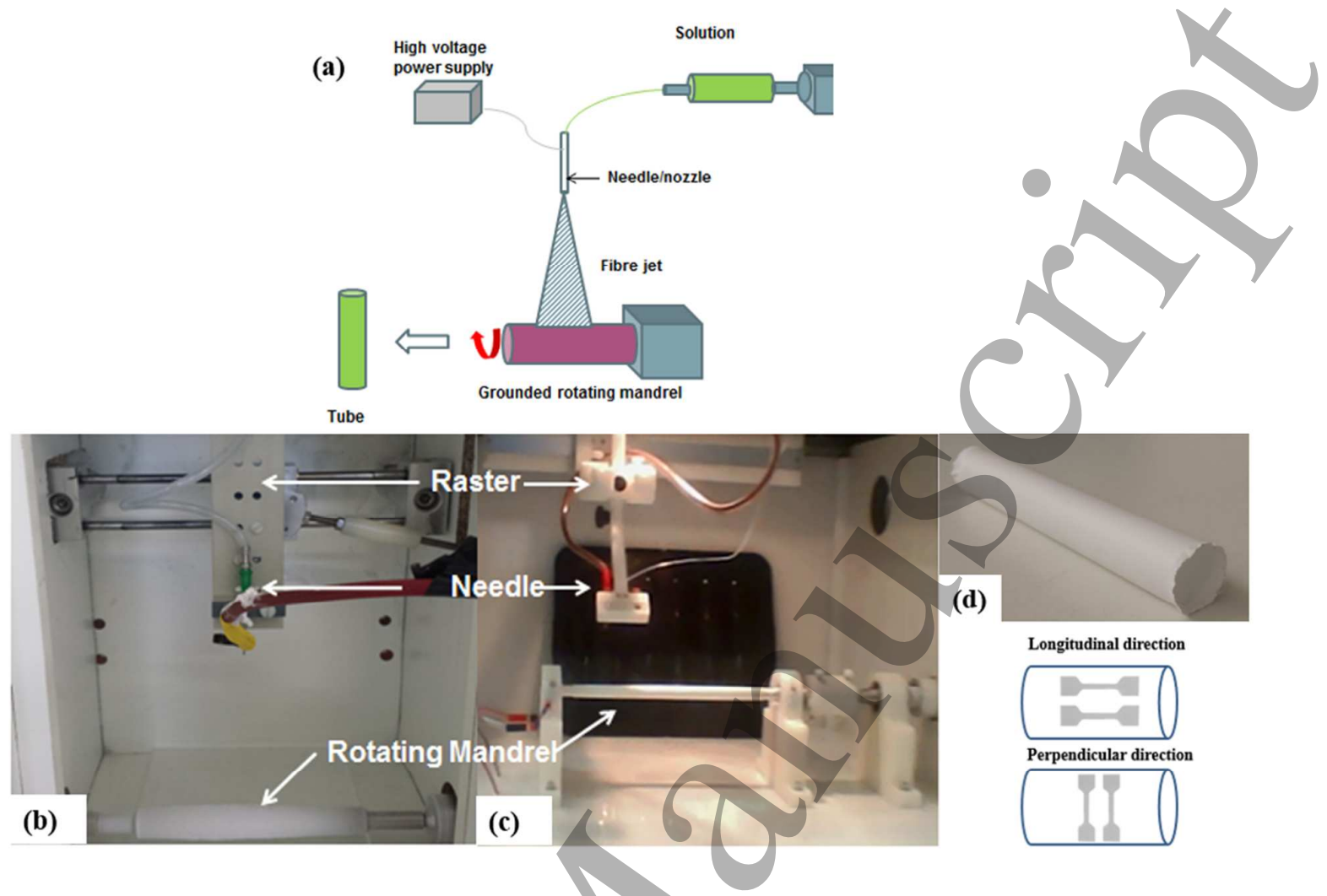

Figure 1. (a) A schematic diagram of the electrospinning process, and images of (b) the custom built electrospinning unit and (c) the NEU-BM commercial instrument used to electrospin (d) polydioxanone tubes in this study. The orientations of the samples taken for mechanical properties testing are also marked in (d).

Electrospinning was first carried out on an instrument built in-house with a maximum mandrel rotation speed of 170 RPM (Fig. 1b). The first parameter to be tested was the volume of liquid dispensed. Scaffolds were electrospun at $5.5 \mathrm{kV}, 25 \pm 4{ }^{\circ} \mathrm{C}$ and with relative humidity in the range of $35-45 \%$. Experiments were performed at constant rotation rate and flow rate (Table 1). The other two electrospinning parameters (flow rate and mandrel rotation speed) were investigated inside a commercially available instrument (NEU-BM; Tong Li Co., Shenzhen, China; Fig. 1c). This allowed us to study higher mandrel rotation speeds and also featured a climate control system to regulate temperature and humidity at $21 \pm 2{ }^{\circ} \mathrm{C}$ and $20 \pm 4 \%$ respectively. Electrospinning was performed at $11 \mathrm{kV}$ in the NEU-BM instrument. In both cases, the PDO solution was dispensed from a $10 \mathrm{~mL}$ 
plastic syringe mounted on a raster which scanned over a rotating mandrel (18 mm diameter) at 30 $\mathrm{mm} \mathrm{s}^{-1}$. The spinneret-to-collector distance was $12 \mathrm{~cm}$. Liquid flow rates, mandrel rotation speeds, and dispensing volumes were selected on the basis of our previous experience $([5,6]$ and unpublished data) and ensuring a systematic survey of the range of parameters possible on the instruments available. A total of 12 tubes were produced by electrospinning (Fig. 1d; Table 1).

Table 1. The electrospinning parameters investigated.

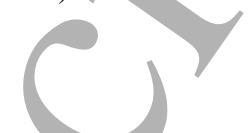

\section{Fibre morphology and alignment}

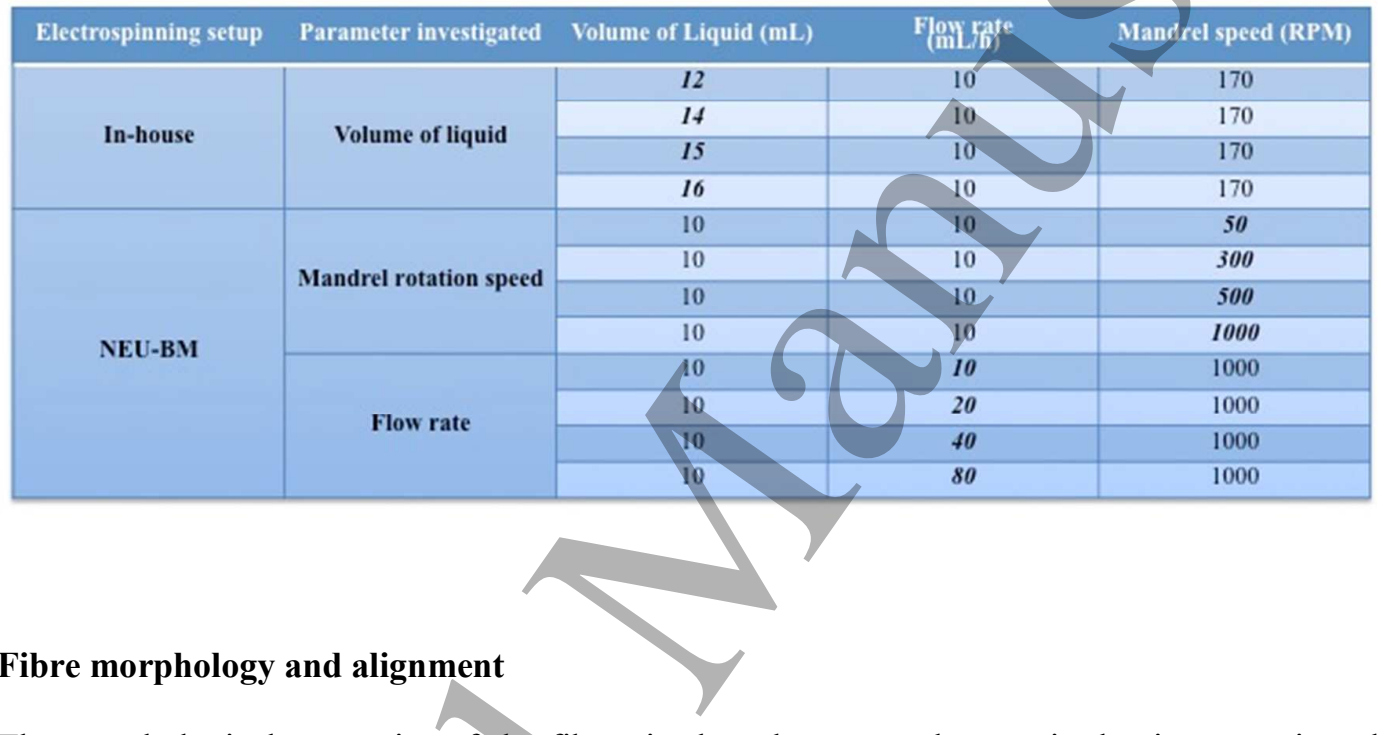

The morphological properties of the fibres in the tubes were characterised using scanning electron microscopy (SEM; Quanta 200 FEG ESEM instrument, FEI, Hillsboro, OR, USA). The images were analysed to determine fibre diameter and porosity using the ImageJ software (National Institutes of Health, Bethesda, ME, USA, http://rsb.info.nih.gov/ij) [11]. To determine porosity characteristics, SEM images were imported into ImageJ software [11]. The process is illustrated in Fig. 2. The original image is displayed in Fig. 2a, and the software set to include the option to calculate the area fraction. Then a threshold histogram (Fig. 2b) was applied to the original image, and the black areas were assumed to be indicative of gaps or pores between the fibres, and colored red (Fig. 2c). The area fraction of the red area was then calculated, as shown in Fig. 2d. A number of studies have shown this method to be an effective way to establish the porosity of electrospun fibres and scaffolds [12-13]. 


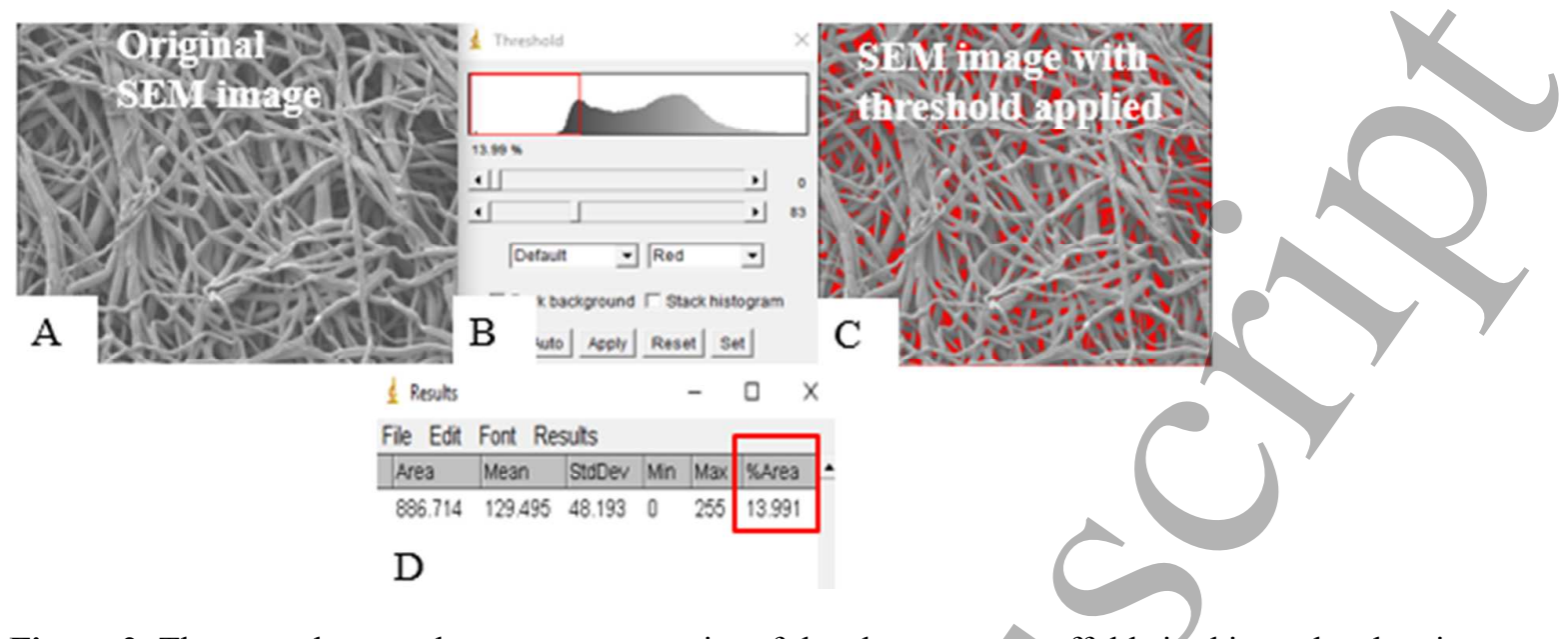

Figure 2. The procedure used to measure porosity of the electrospun scaffolds in this study, showing (a) the original SEM image, (b) the threshold histogram, (c) the SEM image with threshold applied, and (d) the area fraction.

The Fast Fourier Transform (FFT) was used to characterize fibre alignment as a function of mandrel rotation speed. This method has been reported in numerous studies [14-16] and involves the use of FFT output images containing grayscale pixels distributed in a pattern that reflects the degree of fibre alignment in the original image. A graphical depiction of the FFT frequency distribution can be generated by placing a circular projection on the FFT output image and conducting a radial summation of the pixel intensities for each degree between $0^{\circ}$ and $360^{\circ}$, in $1^{\circ}$ increments. The summed value of the pixel intensity can then be plotted as a function of angle. In our analysis, the pixel intensities were summed and then plotted between 0 and $180^{\circ}$ (the FFT is symmetric about the horizontal axis so a pixel summation to $360^{\circ}$ is unnecessary). In all images, the FFT data set has been rotated $90^{\circ}$ to correct for the mathematical transformation inherent to this type of analysis, allowing the principal axis of orientation to be directly determined from the position of the peak in the intensity plot. The amount of alignment present in the original data image is reflected by the height and overall shape of the peak in this plot. For our analyses, digitized SEM images were converted to 8-bit grayscale TIF files. SEM images were cropped to $943 \times 943$ pixels and processed with the ImageJ software supported by an oval profile plug-in [11]. All FFT data were normalized to a baseline value of 0 and plotted in arbitrary units, allowing different data sets to be directly compared. 


\section{Physical form characterization}

The physical form of the polymer in the fibre mats was characterised using differential scanning calorimetry (DSC; Q2000 instrument, TA Instruments, New Castle, DE, USA) and X-ray/diffraction (XRD; Miniflex 600 instrument, Rigaku, Tokyo, Japan). For DSC, samples were equilibrated at $-50^{\circ} \mathrm{C}$ under a flow of $\mathrm{N}_{2}$ gas and a modulated temperature experiment run from -50 to $20{ }^{\circ} \mathrm{C}$ using a temperature ramp of $3{ }^{\circ} \mathrm{C} \mathrm{min}^{-1}$ and a modulation period of $60 \mathrm{~s}$. XRD patterns were acquired over the $2 \theta$ range 3 to $40^{\circ}$ at a speed of $5^{\circ} \min ^{-1}$.

\section{Residual solvent content}

Thermogravimetric analysis (TGA) and gas chromatography (GC) were performed to determine if any residual solvent remained in the scaffolds after spinning. For TGA, samples ( $c a .4 \mathrm{mg}$ ) were heated at $20{ }^{\circ} \mathrm{C} \mathrm{min}^{-1}$ from 2 to $200{ }^{\circ} \mathrm{C}$ under a flow of nitrogen gas $\left(25 \mathrm{~mL} \mathrm{~min}{ }^{-1}\right)$. For GC, samples $(1 \mathrm{mg})$ were dissolved in chloroform, filtered through a $0.45 \mu \mathrm{m}$ filter and analysed using a HP-5 column (injection volume: $0.5 \mu \mathrm{L}$; sampling time $1 \mathrm{~min}$; injector/detector temperatures: $225 / 300{ }^{\circ} \mathrm{C}$. $\mathrm{H}_{2}\left(35 \mathrm{~mL} \mathrm{~min}^{-1}\right)$ and air $\left(350 \mathrm{~mL} \mathrm{~min}^{-1}\right)$ were employed as carrier gases.

\section{Mechanical testing}

The mechanical properties of the tubes were measured following ISO standard 527-2 at $50 \%$ humidity and $23{ }^{\circ} \mathrm{C}$ using a QT50 LP instrument (MTS; Eden Prairie, MN, USA). A load cell of 100 $\mathrm{N}$ was used. Dumb-bell shaped strips of $50 \mathrm{~mm}$ by $8.5 \mathrm{~mm}$ were cut from the tube under test in both the longitudinal direction and perpendicular direction (i.e. at $90^{\circ}$ to the direction of mandrel rotation; see Fig. 1d). The tubes were subjected to a uniaxial tensile test in two steps. First, the samples were elongated at $1 \mathrm{~mm} \mathrm{~min}^{-1}$ until $1 \%$ deformation was observed in order to allow us to measure the Young's modulus using a video extensometer. The samples were the returned to their initial length and elongated at $20 \mathrm{~mm} \mathrm{~min}^{-1}$ until failure, allowing the strength (MPa) and strain (\%) at failure to be quantified. Data are expressed as mean \pm S.D. from at least three measurements. 


\section{In-vitro studies}

\section{Mesenchymal stem cell (MSC) isolation}

Human mesenchymal stem cells (MSCs) were isolated from umbilical cord blood from full-term deliveries and were collected with informed consent. Mononucleated cells were isolated and cultured in alpha-MEM medium (GibCo, Paris, France) supplemented with $10 \% \mathrm{v} / \mathrm{v}$ foetal bovine serum (FBS) and $1 \% \mathrm{v} / \mathrm{v}$ antimycotic-antibiotic (ATM-ATB; Issy Les-Moulineaux, France) at $37^{\circ} \mathrm{C}$ under a $95 \%$ humidified atmosphere and $5 \% \mathrm{CO}_{2}$. Adherent cells were kept in culture until the outgrowth of fibroblast-like cells was observed. At confluence, cultures were haryested with trypsin $(0.05 \%)$ and passaged into a new flask for further expansion.

\section{Cell phenotyping}

Cells were washed in phosphate-buffered saline (PBS) and incubated for 30 minutes at $4{ }^{\circ} \mathrm{C}$ with monoclonal antibodies against human cell surface antigens. Cells were analysed on a FACSCalibur flow cytometer (Becton Dickinson, Paris, France) using Cell Quest Pro (version 4.0.2; Becton Dickinson, Paris, France).

\section{Cell adhesion assay}

To evaluate biocompatibility and cell adhesion, MSCs were loaded onto PDO tube samples and cultured for 3 days before cell viability was determined using the (3-[4,5-dimethylthiazol]-2.5diphenyltetrazolium bromide; thiazyl blue) (MTT) test. Samples $(1 \times 1 \mathrm{~cm})$ were incubated with 0.7 $\mathrm{mL}$ of cell suspension containing $2.5 \times 10^{5}$ or $5 \times 10^{5} \mathrm{MSCs}$ for $72 \mathrm{hrs}$. Subsequently, the cell culture medium was replaced by $0.5 \mathrm{~mL}$ PBS (supplemented with $2.5 \% \mathrm{v} / \mathrm{v}$ FBS), and $50 \mu \mathrm{L}$ MTT solution (Sigma Aldrich, Saint Quentin Fallavier, France) was added. The resultant mixture was incubated for $3 \mathrm{~h}$. Cells were then solubilized with acidic isopropanol containing Triton-X-100. The absorbance of the solution was quantified at $570 \mathrm{~nm}$ with background subtraction at $630-690 \mathrm{~nm}$ on a microplate reader (EL800; Biotek, Paris, France). Three independent experiments were performed, with conditions in triplicate in each experiment. 
Cytotoxicity evaluation

The cytotoxic potential of the electrospun tubes was evaluated by incubating cells in the presence of leachable extracts. Cell viability was determined based on both mitochondria activity (MTT test) and cell membrane integrity (LDH activity test). $1 \times 1 \mathrm{~cm}^{2}$ sections from the PDO tubes were added to alpha-MEM supplemented with $5 \% \mathrm{v} / \mathrm{v}$ FBS and $1 \% \mathrm{v} / \mathrm{v}$ ATM-ATB for $48-72 \mathrm{hrs}$ at $37^{\circ} \mathrm{C}$. Supernatants were collected, centrifuged at $310 \mathrm{~g}$ for $5 \mathrm{~min}$, and stored at $-20^{\circ} \mathrm{C}$ until required for analysis. MSCs were seeded into a 96-well plate at $1 \times 10^{4}$ cells per well, in a volume of $150 \mu \mathrm{L}$, and maintained in culture for $24 \mathrm{~h}$. The cell culture medium was then removed and replaced by increasing concentrations of the supernatants in which the PDO patches had been immersed. The cells were then incubated for a further $48 \mathrm{~h}$, before the culture supernatants were transferred into a fresh 96-well plate and assayed for LDH activity using a LDH cytotoxicity assay (ThermoFisher Scientific Pierce, Courtaboeuf, France). Absorbance was quantified at $490 \mathrm{~nm}$ with background subtraction at $680 \mathrm{~nm}$, using a Spectro Xwave instrument (IUH platform, Hayem Center, Paris-Diderot University, France). In parallel, viability was also determined by staining cells with the MTT reagent as described above.

\section{Data analysis}

Data are reported as mean \pm S.D. Comparisons of the findings across groups for each concentration were performed using analysis of variance, with multiple comparisons performed using pairwise comparisons and the Tukey correction for post-hoc tests. For multiple comparisons with a control group (5\% SVF), the Dunnett correction was used. A two-tailed p-value $<0.05$ was considered statistically significant. Analyses were conducted using SAS 9.4 (Statistical Analysis System, Cary, NC, USA).

\section{Results}

Fibre morphology, diameter, alignment and porosity

The average fibre diameter and porosity of the electrospun tube samples were explored using SEM images of sections cut from each tube. No discernable differences were observed between the tubes 
with different fluid volumes (Fig. 3): all the fibres are approximately cylindrical in shape. For the materials prepared at different flow rates, the fibre morphology appears to become increasingly irregular as the flow rate increases, expected to arise because elevated flow rates do not allow the solvent from the solution to evaporate quickly enough for uniform fibres to form.

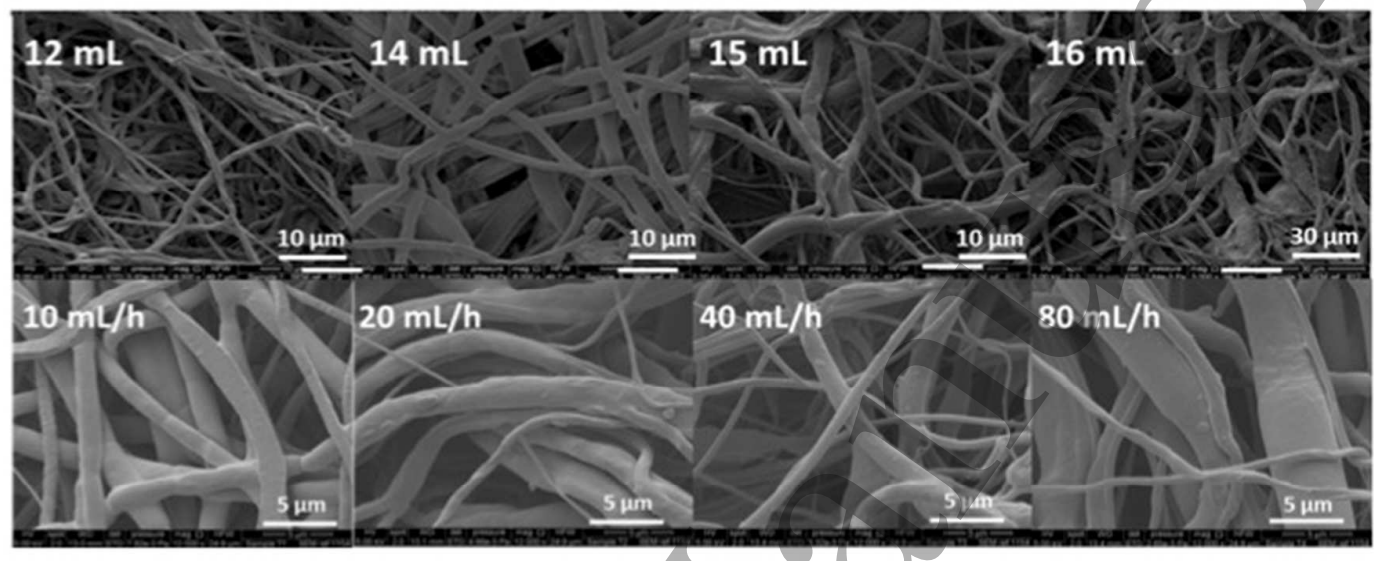

Figure 3. SEM images of polydioxanone tubes produced with increasing volumes of solution (top) and flow rates (bottom).

The fibres prepared at different mandrel rotation speeds are all also largely cylindrical (Fig. 4a-d). The effect of mandrel rotation speed on fibre alignment was determined using FFT analysis. This was performed by assigning a numerical value to fibre alignment. A circular projection was first placed on the FFT output images (Fig. 4e-h) and a radial summation of the pixel intensities for each degree undertaken. The degree of fibre alignment in a data image is represented by the height and shape of the peak generated by the FFT plot (Fig. 4i-iv). The higher the peak, the more precisely aligned the fibres are along a single axis of orientation. The electrospun scaffolds do not exhibit any overt evidence of significant alignment at any rotation speed (Fig. 4i-iv). However, the total area under the curve increased with a rise in rotation rate from 50 to 500 RPM, and then declined slightly at 1000 RPM (areas are: 50 RPM, 12.21 a.u.; 300 RPM 18.18 a.u.; 500 RPM, 21.02 a.u.; 1000 RPM, 16.80 a.u.). From 50 to 300 RPM, the FFT alignment peak maximum increased from 0.7 to 0.8 a.u. as expected but a small decrease of 0.05 units was observed at 500 RPM. The peak FFT alignment value 
measured was at 1000 RPM. These data are consistent with a modest increase in fibre alignment with the rotation rate of the mandrel.
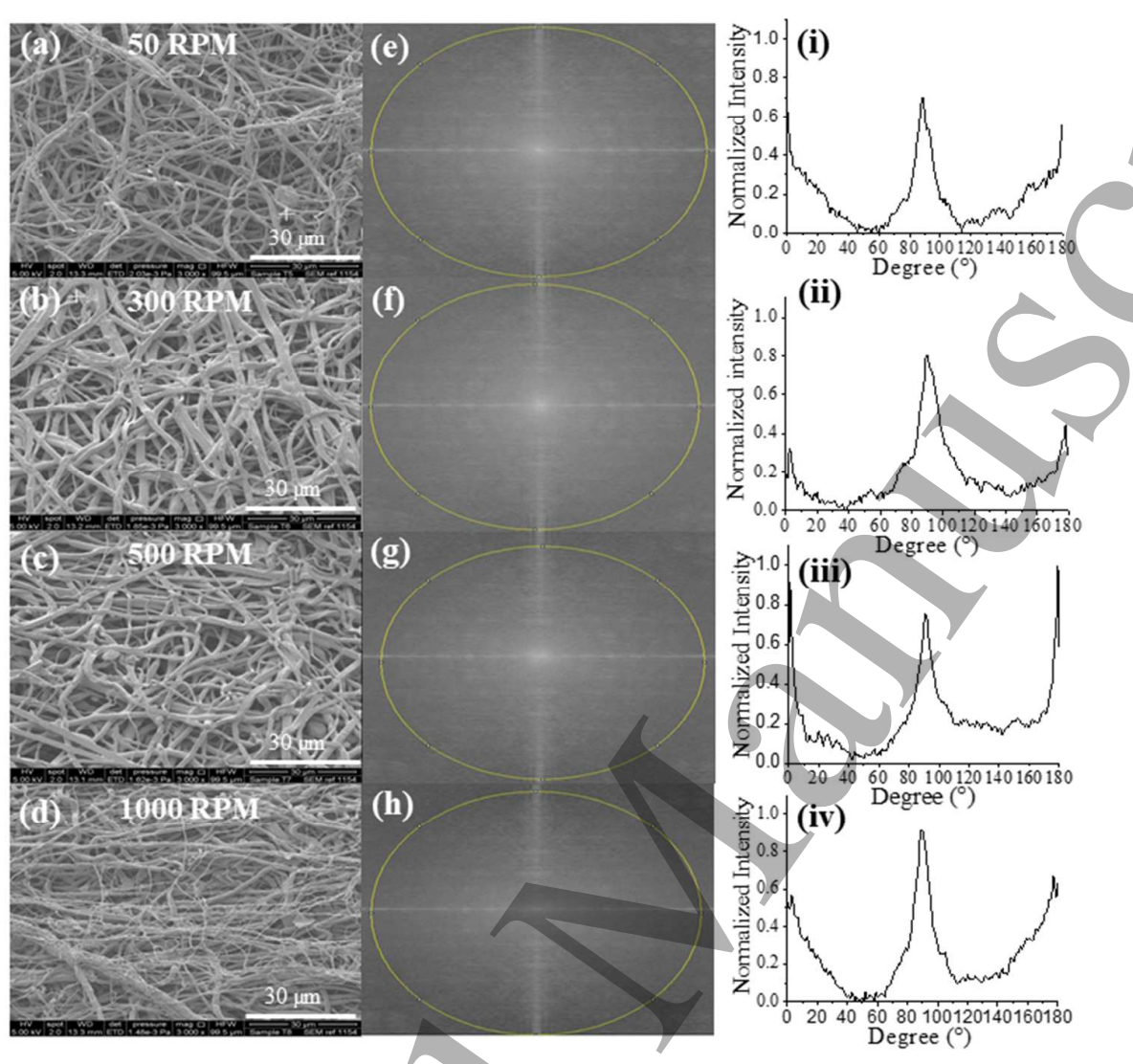

Figure 4. SEM images of $(a-d)$ PDO tubes prepared at increasing mandrel rotation speeds, with $(e-$ h) their circular projections of the Fast Fourier Transformation output, and (i - iv) radial summation of the pixel intensities.

The average fibre diameter and porosities for all the tubes are presented in Fig. 5. Higher volumes of liquid ( $\geq 14 \mathrm{~mm}$ ) and intermediate mandrel rotation speeds (300-500 RPM) appear to result in the largest fibres, while the tubes are more porous with lower flow rates $(\leq 40 \mathrm{~mL} / \mathrm{h})$. Overall, the smallest average fibre diameter was found to be in the tube electrospun at 1000 RPM and the tube with the highest porosity was the one spun with $15 \mathrm{~mL}$ liquid. 

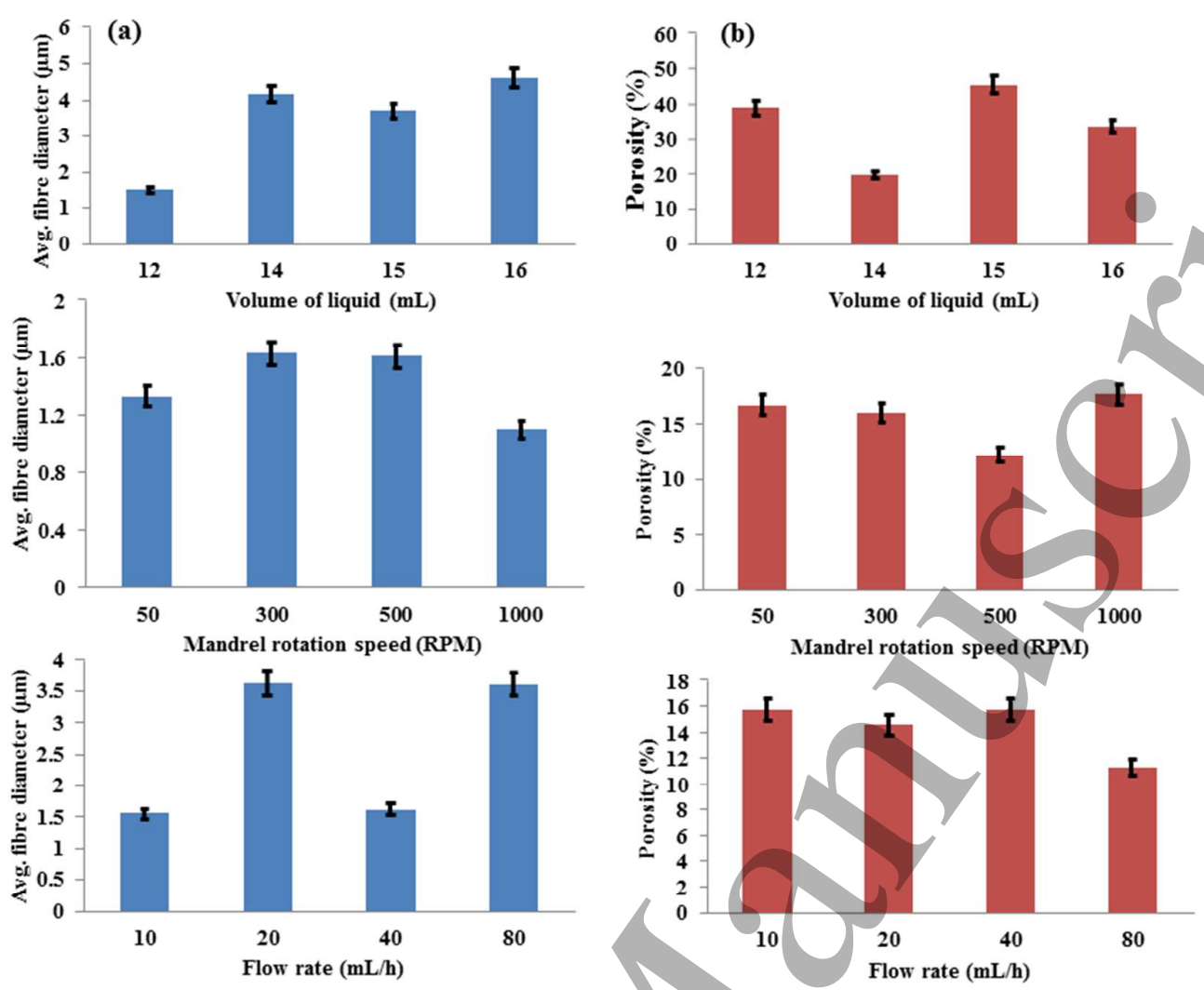

Figure 5. Average fibre diameters (a) and porosities (b) of the polydioxanone scaffolds prepared with increasing volumes of liquid (top), mandrel rotation speeds (middle) and flow rates (bottom). The error bars indicate the standard deviation.

\section{Physical form}

Fig. 6 shows the XRD patterns for all the tubes made. The PDO tubes are semi-crystalline, as is the pure polymer, with two distinct Bragg reflections visible between $21^{\circ}$ and $23^{\circ}$ in all the diffraction patterns. DSC was performed to determine the glass transition temperatures $\left(T_{g}\right)$ of the tubes (Fig. 6). The glass transition temperature of raw PDO is reported to be between -10 and $0{ }^{\circ} \mathrm{C}$ [17]. All the electrospun tubes had a $T_{\mathrm{g}}$ below this range, from -10 to $-24^{\circ} \mathrm{C}$. The tubes electrospun on the in-house setup at 170 RPM had consistently lower $T_{g}$ values than those produced on the NEU-BM instrument. The electrospinning process thus exerts a plasticizing influence on the polymer. This arises because the process is very rapid, with the solidification process occurring in well under $1 \mathrm{~s}$, leading to a reduction in the number of crystalline domains present (c.f. the pure polymer) and hence to the overall 
composite transitioning from brittle to ductile at a lower temperature. The inclusion of small amounts of solvent or water from the surrounding air could also contribute to this phenomenon.
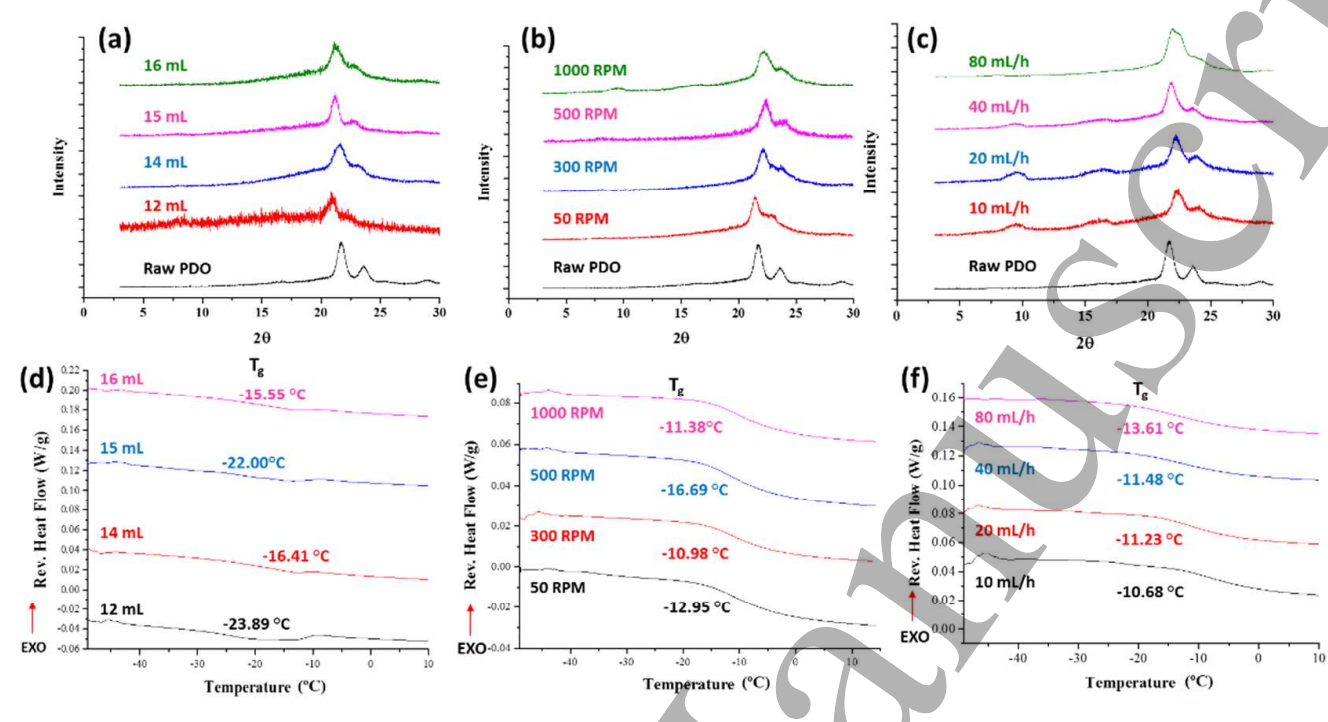

Figure 6. X-ray diffraction (XRD) and differential scanning calorimetry (DSC) patterns for tubes generated using increasing volumes of solution $(\mathrm{a}, \mathrm{d})$, mandrel rotation speeds $(\mathrm{b}, \mathrm{e}$; flow rate 10 $\mathrm{mL} / \mathrm{h}$ ), and flow rates (c,f; mandrel rotation speed $1000 \mathrm{rpm})$.

\section{Solvent content}

TGA showed very little mass loss below $250^{\circ} \mathrm{C}(<2.5 \%)$, indicating that there was very little solvent present in the tubes after drying. We verified these findings with gas chromatography (GC; Fig. 7), using tube samples dissolved in chloroform. The GC data for pure chloroform shows peaks at 0.68 and $0.92 \mathrm{~min}$, and when chloroform is spiked with $1 \%$ HFIP an additional peak at 0.75 min can be seen. The latter is thus clearly diagnostic of HFIP. Regardless of the drying method used, none of the tube samples analysed showed any GC peak at $0.75 \mathrm{~min}$, confirming the absence of HFIP in the tubes. 

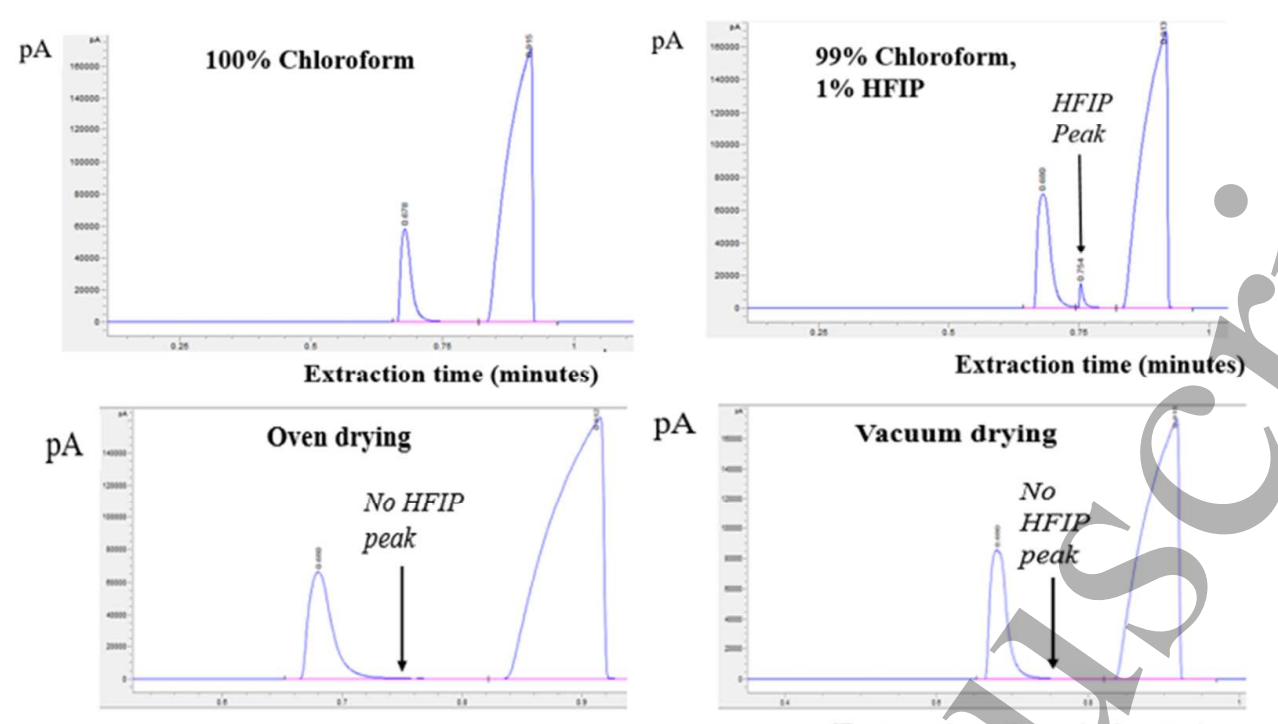

$\mathrm{pA}$

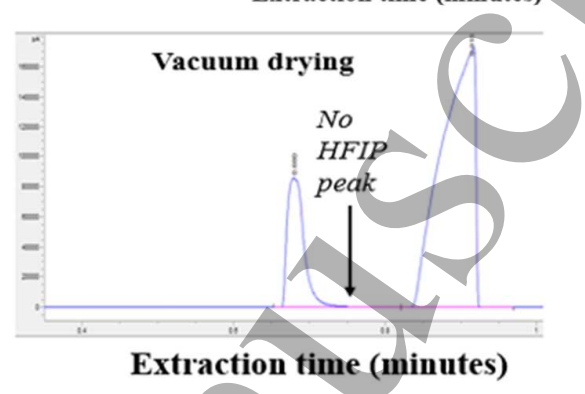

Extraction time (minutes)

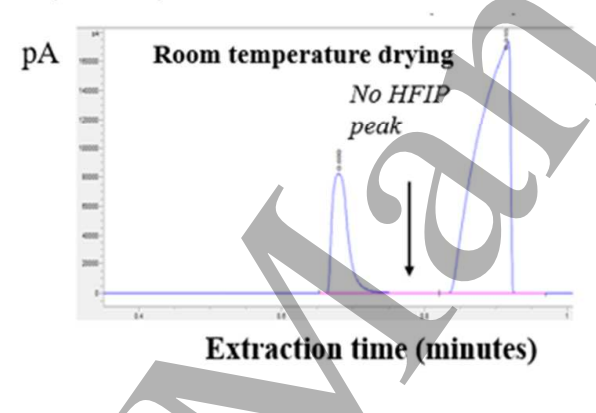

Figure 7. Gas Chromatography data showing the absence of any HFIP solvent residue in a polydioxanone tube after three different drying processes (at room temperature, in an oven at $35^{\circ} \mathrm{C}$, or in a vacuum oven at $37^{\circ} \mathrm{C}$ ). HFIP: 1,1,1,3,3,3-hexafluoro-2-propanol

\section{Mechanical testing}

The mechanical properties data on all the tubes electrospun with the three different electrospinning parameters are displayed in Fig. 8. The volume of liquid has a slight effect on the mechanical properties of the tube in both the longitudinal and perpendicular loading directions: the stress at failure and modulus of the tubes increase with the volume of liquid spun up to $15 \mathrm{~mL}$, before both decrease at $16 \mathrm{~mL}$. There is no clear pattern in the strain to failure data. The effect of mandrel rotation speed on the mechanical properties of tubes prepared at $10 \mathrm{~mL} / \mathrm{h}$ in both directions of loading is more pronounced, but non-linear. Stress, strain and elasticity (modulus) all exhibit peak values at 500 RPM followed by a decrease at 1000 RPM, indicating that fibre anisotropy is increasing with the speed of 
mandrel rotation and hence is affecting the modulus of the tubes. Flow rate also has a notable effect on the stress and modulus values of tubes generated with a mandrel rotation rate of $1000 \mathrm{rpm}$ : both stress and modulus have the lowest values at $20 \mathrm{~mL} \mathrm{~h}^{-1}$ followed by an increase at $40 \mathrm{~mL} \mathrm{~h}^{-1}$. Strain to failure shows a different pattern, with the minimum strain obtained at $40 \mathrm{~mL} \mathrm{~h}^{-1}$. 

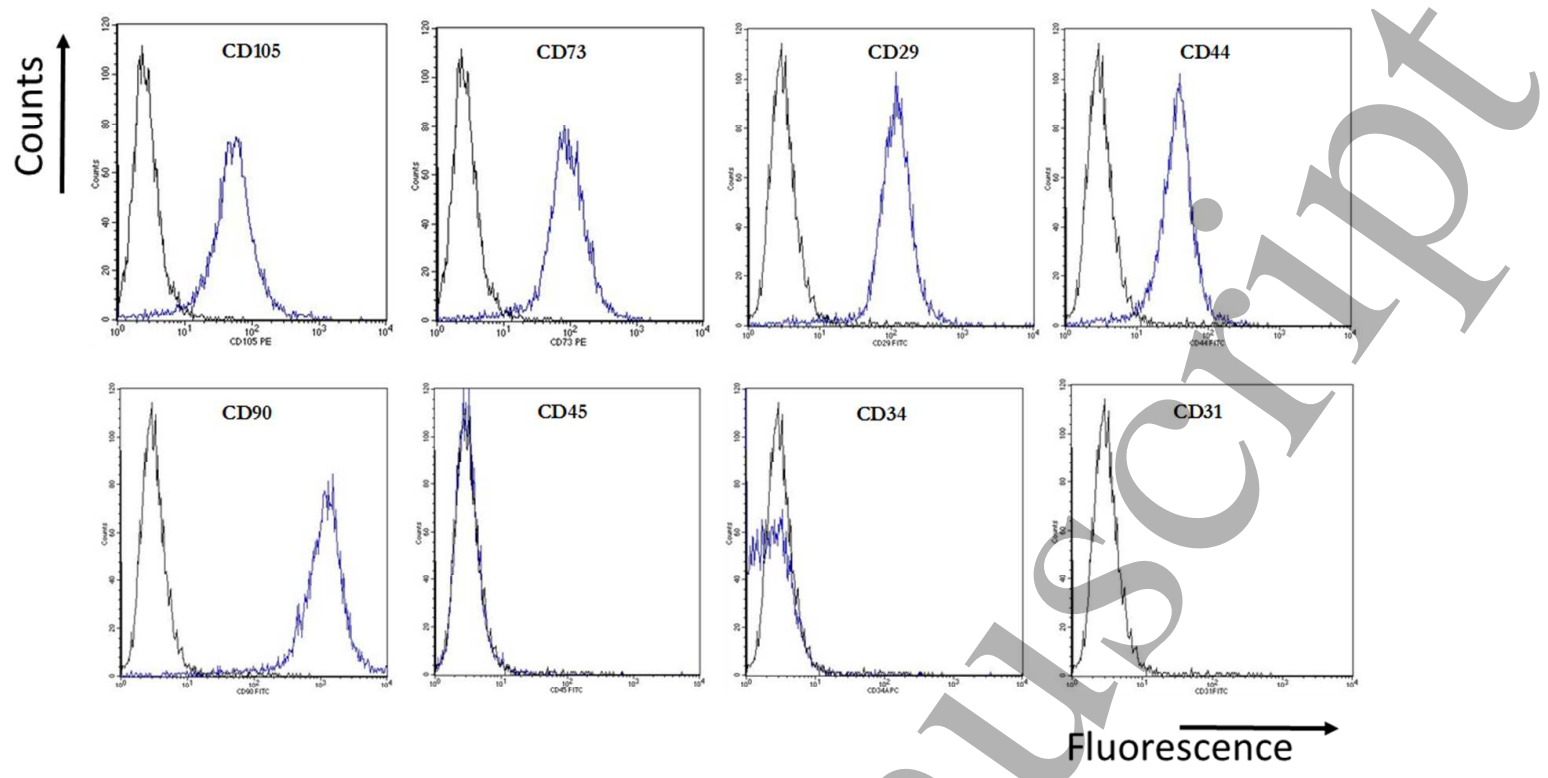

Figure 9: Phenotyping of mesenchymal stem cells. Representative flow cytometry data used to characterize expanded MSC, showing the staining antibody (blue histogram) vs. corresponding isotype (black histogram).

Fig. 10 displays the results of the viability and cytotoxicity tests. The MTT assay showed viable and metabolically active cells grew on all the tubes samples, with no significant differences between the various spinning conditions (Fig. 10a). Cytotoxicity assays, based on LDH release in supernatants (Fig. 10b), showed the absence of any detrimental effects of the polymer - regardless of the different electrospinning conditions - on the cell membrane integrity. At low flow rates (10 and $20 \mathrm{~mL} / \mathrm{h})$, LDH release is slightly decreased, suggesting a possible modification in cell membrane permeability, but no severe impact on cell metabolism can be seen by MTT analysis (Fig. 10c). Overall, these data show that exposure to the electrospun tubes leads to no significant change in mitochondria activity, based on MTT results, nor on cell membrane integrity (evidenced by LDH results). It might be that increasing the flow rate might avoid any disturbance in cell membrane integrity and cell metabolism, but no clear conclusions can be drawn in this regard. 


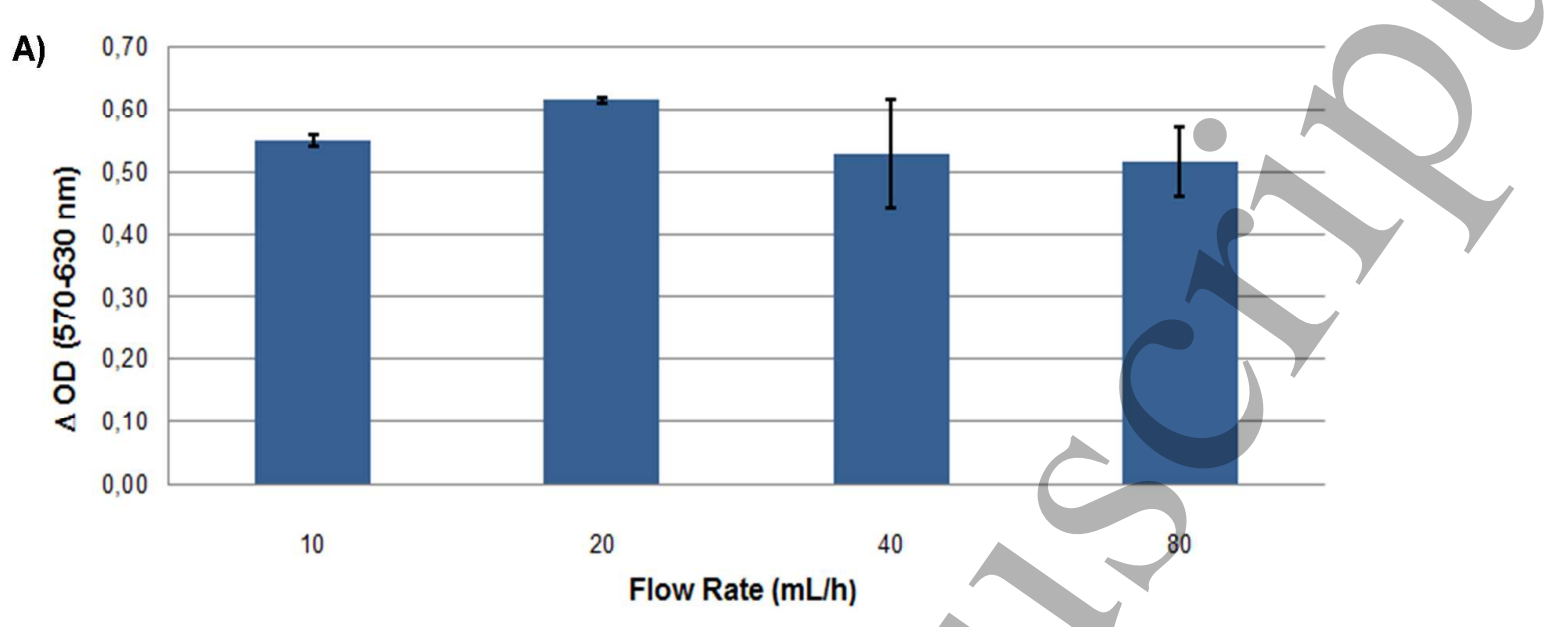

B)

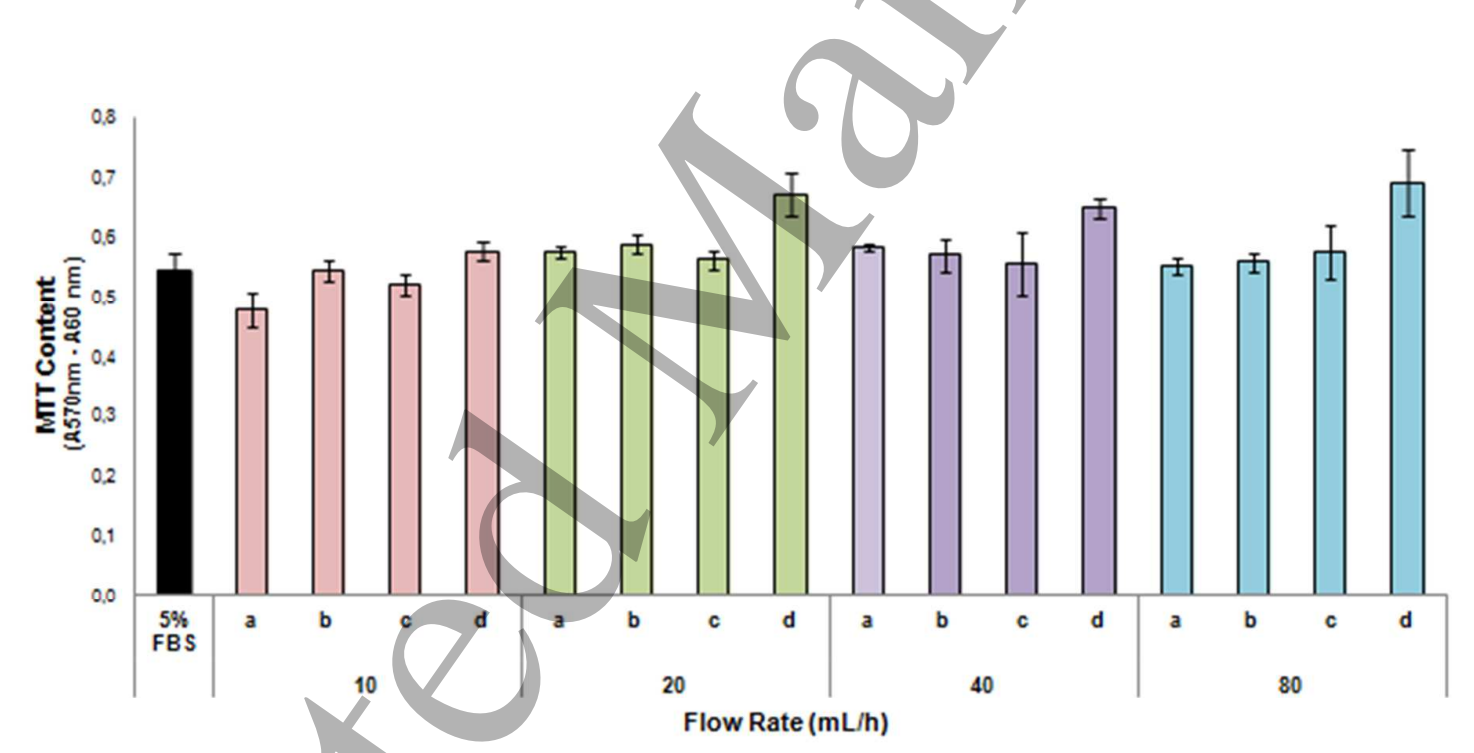


C)

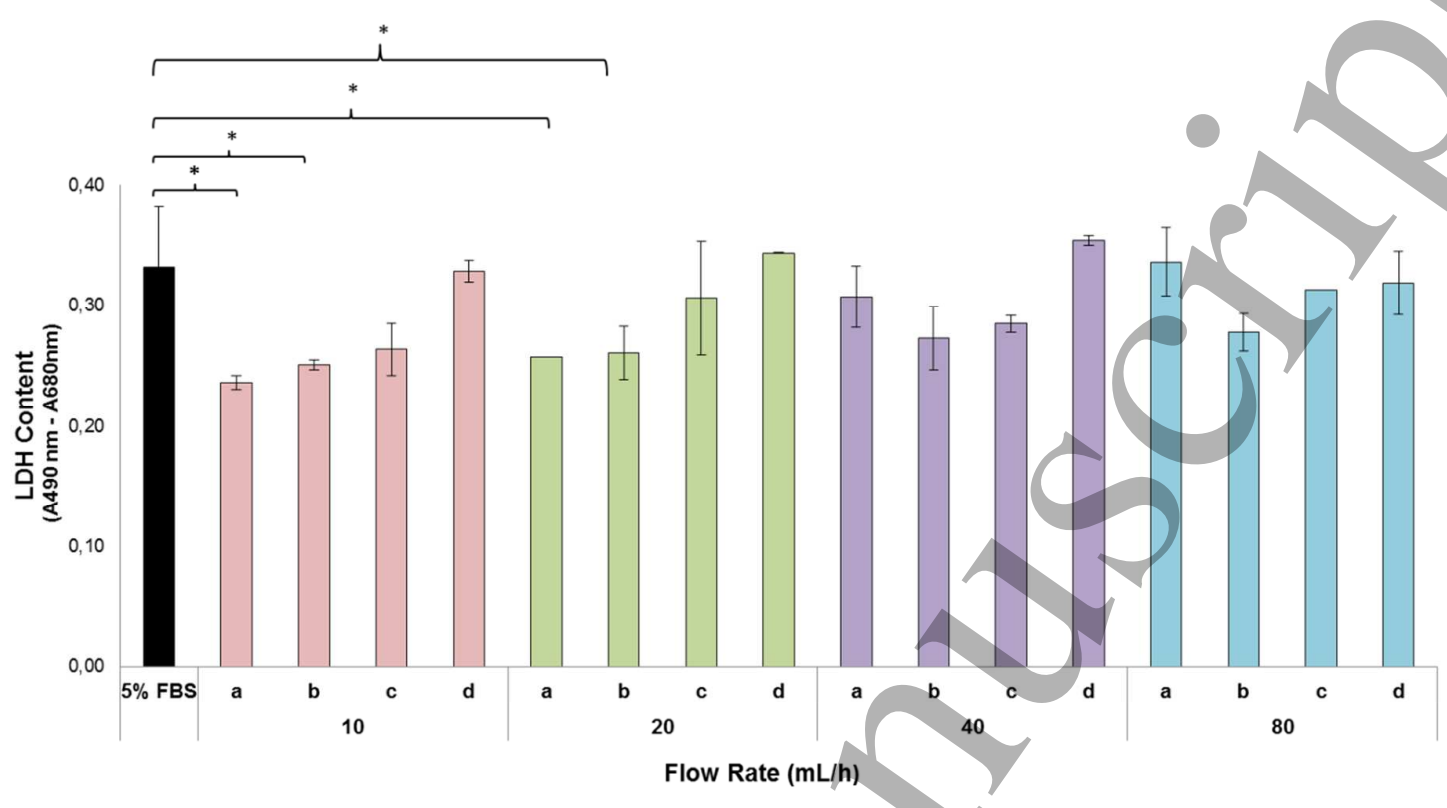

Figure 10. In vitro biocompatibility tests with samples prepared at different flow rates: (A) mesenchymal stem cell adhesion tests; (B) MTT cytotoxicity assay and (C) LDH cytotoxicity assay results with varied dilutions of the supernatant. $\mathrm{a}=100 \% \mathrm{v} / \mathrm{v}, \mathrm{b}=75 \% \mathrm{v} / \mathrm{v}, \mathrm{c}=50 \% \mathrm{v} / \mathrm{v}, \mathrm{d}=25 \% \mathrm{v} / \mathrm{v}$. MTT: (3-[4,5-dimethylthiazol]-2.5-diphenyltetrazolium bromide; thiazyl blue); LDH: Lactate DeHydrogenase. $*$ denotes a significant difference from the positive control $(\mathrm{p}<0.05)$. There are no significant differences between the samples and controls in the adhesion tests or MTT data.

\section{Discussion}

A general strategy for biodegradable scaffolds aiming at replacing the RVOT in children with a congenital heart defect is to mimic the dimensions, biological activity and mechanical properties of the extracellular matrix. This can be achieved by developing processes that allow structures with a fibre diameter, pore size, porosity, and fibre alignment that mimic in vivo conditions to be fabricated [18]. Electrospinning can produce constructs with a degree of control over fibre diameter and porosity; however, this control can only be achieved by optimising the electrospinning parameters [19]. PDO was explored in this work because of its excellent biocompatibility, as demonstrated by our group and others $[5,6,20]$, and its clinical use in human cardiac surgery as suture materials or a 
prosthetic ring with a long-standing safety record in children and excellent mechanical properties [21].

We showed that increasing mandrel rotation speed increases fibre alignment, stress at failure and Young's modulus, also increasing the scaffold anisotropy. Fibre morphology appears to become increasingly irregular as the flow rate increases. An increase of flow rate also raises the rigidity of the tubes (which manifests itself as an increase of the Young's modulus and decrease of the strain at break). These results confirm the impact of electrospinning parameters on the fibre morphology, alignment and mechanical properties of the scaffolds.

A precise optimization and control of these parameters is required to create, in a reproducible way, scaffolds for RVOT tissue engineering possessing the ultrastructural and mechanical features required to ensure appropriate in vivo behaviour after implantation. We noted a substantial decrease in porosity for sets of experiments performed on the NEU-BM instrument compared to the set performed on an assembly built in-house. This could be attributed to fact that much better control of temperature and humidity were possible with the NEU-BM instrument. This reinforces the concept that control of these parameters is vital in ensuring the production of tubes with consistent properties, and needs to be taken into account in future translational developments.

The glass transition $\left(\mathrm{T}_{\mathrm{g}}\right)$ temperatures for the tubular scaffolds were lower than that of unprocessed $\mathrm{PDO}$, which is in accordance with literature reporting that electrospun fibres often show $\mathrm{T}_{\mathrm{g}} \mathrm{s}$ different from the bulk material owing to variation in molecular orientation following the electrospinning process $[22,23]$. Such a decreased $T_{g}$ is relevant from a clinical standpoint since a $T_{g}$ much lower than the physiological temperature in humans $\left(37^{\circ} \mathrm{C}\right)$ will ensure the scaffold behaves in an elastic manner after implantation, with no risk of brittleness and fracture.

This study is part of a program targeted at developing a resorbable valved tube for replacement of the RVOT. The mechanical properties of the PDO electrospun tubes obtained in this work can usefully be 
compared to those of the native pulmonary artery and pulmonary valve cusps. The native pulmonary valve cusps exhibit in the circumferential direction a range of Young's modulus of 2.6-15 MPa, a tensile stress of 0.8-2.6 MPa and a strain at failure of 1.6- $22 \%$ [24]. The pulmonary artery has a Young's modulus of $0.04-1.69 \mathrm{MPa}$, a tensile stress of $0.38-0.95 \mathrm{MPa}$ and a strain at failure of $91-$ $175 \%$ [24]. The Young's moduli of the PDO tubes prepared in this work range from 5 to $60 \mathrm{MPa}$ in circumferential direction (Fig. 7). A Young's modulus $<15 \mathrm{MPa}$, close to that of the native tissue, was obtained with a low mandrel speed $(<300 \mathrm{RPM})$ for any volume of liquid. Similarly, the tensile stress of PDO tubes in the circumferential direction ranges from 2 to $12 \mathrm{MPa}$; a tensile stress of $<2.5$ $\mathrm{MPa}$, close to the native valve tissue, was obtained with a low mandrel speed (50 RPM), again with any volume of liquid. Finally, strain at failure values of PDO tubes in the circumferential direction vary from 10 to $300 \%$ (Fig. 7). A strain at failure of $<175 \%$, close to the native tissue, was obtained at a flow rate of $>20 \mathrm{~mL} / \mathrm{h}$, at any mandrel rotation speed and with any volume of liquid. These results demonstrate the impact of the electrospinning parameters on specific mechanical properties, and further show that optimising the electrospinning process can successfully yield polymer-based tubes with mechanical properties close to those of the native pulmonary artery and pulmonary valve cusps.

From a biological standpoint, cell adhesion and cytotoxicity assays indicated that MSCs could attach and remain viable onto all the tubes prepared. These data confirm the excellent biocompatibility of PDO and of highly porous polymeric scaffolds, and suggest that the electrospinning parameters do not materially affect biocompatibility. Nevertheless, they can have a strong biological impact on cell migration (related to the scaffold porosity) and on cell differentiation and phenotype (related to mechanical properties and stiffness of the scaffold).

This study presents some limitations. First, the impact of electrospinning parameters on cell migration and differentiation was not investigated. Second, we observed some batch-to-batch variability of the samples despite a tight control of electrospinning conditions (especially with the industrial electrospinning machine). This variability was taken into account in the interpretation of the results. 
Finally, a mechanical characterization of the samples under physiological conditions could have more accurately modelled in vivo conditions.

There is an increasing consensus that the primary role of tissue-engineered constructs designed to restore the RVOT is to foster endogenous responses enabling scaffold colonization by host cells, leading to the ultimate generation of an autologous "living" conduit. However, tissue regeneration does not only respond to chemical signals with regard to cell homing, survival, proliferation and differentiation. The regenerative process is also very sensitive to physical cues like the topography and elasticity of the supporting substrate [25-27]. As such, the data reported in this work may be useful for leveraging electrospinning parameters to fine-tune the three-dimensional scaffold architecture and control the patterning of mechanical cues in a way that optimizes mechanical properties of the scaffold on the one hand, and the cell-material interactions critical for an appropriate scaffold repopulation by host-derived cells on the other. The electrospun scaffolds obtained in this study demonstrated clear anisotropic behaviour with significantly different mechanical properties in the longitudinal and perpendicular directions. Given the fact that such behaviour is one of the most important mechanical features of native vascular and valvar tissues, the electrospinning-based generation of medical-grade polymer tubes with anisotropic properties close to the native RVOT could pave the way to a bioresorbable device to replace the RVOT in congenital heart surgery.

\section{Conclusions}

Electrospinning was used to develop tubular scaffolds of polydioxanone (PDO), as part of our efforts to develop bioresorbable replacements for the right ventricle outflow tract (RVOT). Three electrospinning parameters (volume of liquid, flow rate, and speed of mandrel rotation) were investigated and their effect on the mechanical properties and cellular response of the scaffolds explored. The mechanical properties were compared to those of the native RVOT reported in the literature. In all cases, the fibres were approximately cylindrical in morphology, although high flow rates led to increasingly inhomogeneous fibres. Increasing the mandrel rotation speed increased the fibre alignment slightly, and caused larger increases in the stress at failure and Young's modulus. An 


\section{Acknowledgements}

increase in flow rate also increased the rigidity of the tubes. By using a mandrel rotation speed of 50 $\mathrm{rpm}$ and a flow rate of $20 \mathrm{~mL} / \mathrm{h}$ or higher we can prepare materials with Young's modulus, strain at failure, and tensile stress close to the native tissue. Cell viability and cytotoxicity assays showed all the tubes produced to have excellent biocompatibility. Through variation of the processing parameters, it is possible to tune the mechanical properties of the PDO tubes over a wide range, offering great promise in the development of scaffolds to match the anisotropic properties of the native RVOT.

The authors thank Mr David McCarthy of the UCL School of Pharmacy for recording SEM images.

\section{Funding}

This work was supported by the European Union's Seventh Framework Programme for research, technological development and demonstration under grant agreement no 604049.

\section{Conflicts of interest}

None

\section{References}

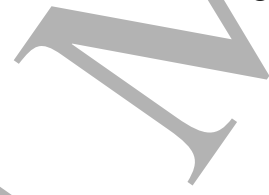

1. Mozaffarian D, Benjamin EJ, Go AS, Arnett DK, Blaha MJ, et al. Heart Disease and Stroke Statistics-2016 Update: A Report From the American Heart Association. Circulation. 2016;133(4):e38-360.

2. Sinzobahamvya N, Boscheinen M, Blaschczok HC, Kallenberg R, Photiadis J, Haun C, et al. Survival and reintervention after neonatal repair of truncus arteriosus with valved conduit. Eur J Cardiothorac Surg. 2008;34(4):732-7.

3. Picard-Deland M, Ruel J, Galbraith T, Tremblay C, Kawecki F, Germain L, et al. TissueEngineered Tubular Heart Valves Combining a Novel Precontraction Phase with the Self-Assembly Method. Annals of biomedical engineering. 2016. 4. Del Gaudio C, Gasbarroni PL, Romano GP. Experimental investigations on the fluidmechanics of an electrospun heart valve by means of particle image velocimetry. Journal of the mechanical behavior of biomedical materials. 2016;64:229-39.

5. Kalfa D, Bel A, Chen-Tournoux A, Della Martina A, Rochereau P, Coz C, et al. A polydioxanone electrospun valved patch to replace the right ventricular outflow tract in a growing lamb model. Biomaterials. 2010;31(14):4056-63. 
6. Pontailler M, Illangakoon E, Williams GR, Marijon C, Bellamy V, Balvay D, et al. PolymerBased Reconstruction of the Inferior Vena Cava in Rat: Stem Cells or RGD Peptide? Tissue Engineering Part A. 2015;21(9-10):1552-64.

7. Hasan A, Ragaert K, Swieszkowski W, Selimovic S, Paul A, Camci-Unal G, et al. Biomechanical properties of native and tissue engineered heart valve constructs. J Biomech. 2014;47(9):1949-63.

8. Telemeco TA, Ayres C, Bowlin GL, Wnek GE, Boland ED, Cohen N, et al. Regulation of cellular infiltration into tissue engineering scaffolds composed of submicron diameter fibrils produced by electrospinning. Acta Biomaterialia. 2005;1(4):377-85.

9. Doshi J, Reneker DH. Selected papers from the special technical session "Electrostatícs in Polymer Processing and Charge Monitoring", 1993 IEEE Industry Applications Society

MeetingElectrospinning process and applications of electrospun fibres. Journal of Electrostatics. 1995;35(2):151-60.

10. Yang F, Murugan R, Wang S, Ramakrishna S. Electrospinning of nano/micro scale poly(1lactic acid) aligned fibres and their potential in neural tissue engineering. Biomaterials. 2005;26(15):2603-10.

11. NIH. Image Processing and Analysis in Java [cited 201511 March]. Available from: https://imagej.nih.gov/ij/.

12. Feng-Lei Zhou, Geoff J.M. Parker, Stephen J. Eichhorn, Penny L. Hubbard Cristinacce, Production and cross-sectional characterization of aligned co-electrospun hollow microfibrous bulk assemblies, Materials Characterization 2015;109: 25-35

13. McCullen, S. D., Stevens, D. R., Roberts, W. A., Clarke, L. I., Bernacki, S. H., Gorga, R. E., \& Loboa, E. G. (2007). Characterization of electrospun nanocomposite scaffolds and biocompatibility with adipose-derived human mesenchymal stem cells. International Journal of Nanomedicine 2007;2(2): 253-263.

14. Ayres C, Bowlin GL, Henderson SC, Taylor L, Shultz J, Alexander J, et al. Modulation of anisotropy in electrospun tissue-engineering scaffolds: Analysis of fibre alignment by the fast Fourier transform. Biomaterials. 2006;27(32); 5524-534.

15. Ayres CE, Bowlin GL, Pizinger R, et al. Incremental changes in anisotropy induce incremental changes in the material properties of electrospun scaffolds. Acta Biomaterialia 2007;3(5): 651-661.

16. Ayres CE, Jha BS, Meredith H, et al. Measuring fiber alignment in electrospun scaffolds: a user's guide to the 2D fast Fourier transform approach. J Biomater Sci Polymer Edn 2008;19(5):60321.

17. Medical Device and Diagnostic Industry. Synthetic Biodegradable Polymers as Medical Devices 1998 [cited 2016 10 June].

18. Lannutti J, Reneker D, Ma T, Tomasko D, Farson D. Electrospinning for tissue engineering scaffolds. Materials Science and Engineering: C. 2007;27(3):504-9.

19. Rnjak-Kovacina J, Wise SG, Li Z, Maitz PK, Young CJ, Wang Y, et al. Tailoring the porosity and pore size of electrospun synthetic human elastin scaffolds for dermal tissue engineering. Biomaterials. 2011;32(28):6729-36.

20. Moshiri A, Oryan A, Meimandi-Parizi A. Synthesis, development, characterization and effectiveness of bovine pure platelet gel-collagen-polydioxanone bioactive graft on tendon healing. Journal of cellular and molecular medicine. 2015;19(6):1308-32.

21. Myers PO, Kalangos A. Valve repair using biodegradable ring annuloplasty: from bench to long-term clinical results. Heart, Lung and Vessels. 2013;5(4):213-8.

22. Liu F, Guo R, Shen M, Wang S, Shi X. Effect of Processing Variables on the Morphology of Electrospun Poly[(lactic acid)-co-(glycolic acid)] Nanofibres. Macromolecular Materials and Engineering. 2009;294(10):666-72.

23. Dhakate SS, B.; Uppal, M. \& Mathur, R. Effect of processing parameters on morphology and thermal properties of electrospun polycarbonate nanofibres. Advanced Materials Letters. 2010;1:2004.

24. Balguid AR, M.P.; Mol, A.; Bank, A.R.; Boggers, Ad J.J.C.; van Kats, J.P.; de Mol, B.A.J.M.; Baaijens, F.P.T. and Bouten, C.V.C,. The role of collagen cross-links in biomechanical 
behavior of human aortic heart valve leaflets - relevance for tissue engineering. Tissue Engineering. 2007;13(7):1501-11.

25. Kim D-H, Lipke EA, Kim P, Cheong R, Thompson S, Delannoy M, et al. Nanoscale cues regulate the structure and function of macroscopic cardiac tissue constructs. Proceedings of the National Academy of Sciences. 2010;107(2):565-70.

26. Cigognini D, Lomas A, Kumar P, Satyam A, English A, Azeem A, et al. Engineering in vitro microenvironments for cell based therapies and drug discovery. Drug Discovery Today. 2013;18(2122):1099-108.

27. Kinney MA, McDevitt TC. Emerging strategies for spatiotemporal control of stem cell fate and morphogenesis. Trends in Biotechnology.31(2):78-84. 